\title{
Tensile and shear bond strength between cement paste and aggregate subjected to high temperature
}

\author{
Y. El Bitouri - F. Jamin • C. Pélissou - M. S. El Youssoufi
}

\begin{abstract}
In the framework of studying the leakage rate of concrete containment of nuclear power plants during an accident, the mechanical characterization of interface between cement paste and limestone aggregate was performed with mechanical tests at the local scale, inside the laboratory of micromechanics and integrity of structures (MISt). The evolution of tensile and shear bond strength between cement paste and aggregate after heating was determined. It was revealed that the tensile bond strength was strongly affected by the temperature rise, with a decrease of about $71 \%$ at $60{ }^{\circ} \mathrm{C}$. Moreover, the shear bond strength increased almost linearly with the increase of normal stress. According to the Coulomb criterion, the cohesion and the internal friction angle were
\end{abstract}

Y. El Bitouri $(\bowtie) \cdot$ C. Pélissou

Institut de Radioprotection et de Sûreté Nucléaire IRSN, B.P. 3, 13115 Saint-Paul-Lez-Durance Cedex, France e-mail: youssef.elbitouri@mines-ales.fr

Y. El Bitouri · F. Jamin · C. Pélissou ·

M. S. El Youssoufi

MIST Lab., IRSN, CNRS, Univ. Montpellier,

Montpellier, France

F. Jamin · M. S. El Youssoufi

LMGC, CNRS, Univ. Montpellier, Montpellier, France

Present Address:

Y. El Bitouri

Centre des matériaux des mines d'Alès (C2MA), Ecole des mines d'Alès, Alès, France determined. These parameters decreased after heating, which indicates occurrence of thermic damage between cement paste and limestone aggregate. Finally, it appears that the tensile bond strength is more affected by the thermal damage than the shear bond strength.

Keywords Tensile strength - Aggregate $\cdot$ Cement paste $\cdot$ Shear strength $\cdot$ Temperature

\section{Introduction}

One of the main concerns in the context of the safety of nuclear installations is the control of the leakage rate of concrete containment of nuclear power plants during an accident. The typical scenario is a loss of coolant accident (LOCA) which can lead to a temperature rise of about $150{ }^{\circ} \mathrm{C}$. The study of concrete mechanical behavior in this context seems therefore essential in order to anticipate the risk of leakage.

Several studies have been conducted on concrete behavior at high temperatures [1-6]. Indeed, when concrete is subjected to a temperature rise, several physicochemical changes occur. These physicochemical changes are accompanied by a loss of mechanical properties and a material damage (cracking). This damage can lead to a loss of containment properties (permeability and porosity), which is very detrimental 
if the material is used in special structures such as containment of nuclear power plants.

Indeed, the main mechanisms responsible for the cracking of the concrete at high temperatures would be due to thermal and moisture transfers that induce an evaporation of water and an increase in pore pressure. However, other mechanisms may also contribute to the damage of concrete at high temperatures, such as high incompatibility of deformations between the matrix (cement paste, mortar) and aggregates [2,7]. This incompatibility of deformations, or thermal mismatch mechanism, causes a preferential cracking at the matrix-aggregate interfaces also called "ITZ" for Interfacial Transition Zone. Most models [7-10] on the behavior of concrete at high temperatures do not explicitly account for the latter mechanism due to the difficulty to estimate the properties of interfaces.

ITZ is a heterogeneous area of the cement paste around the aggregate particles where the microstructure is modified by the presence of the aggregate (porosity gradient, gradient of anhydrous and hydrated phases). This region originates from the so-called "wall" effect of packing of cement grains against the relatively flat aggregate surface and the micro-bleeding $[11,12]$. Different investigations have been performed to understand the microstructure of this transition zone [11-13], because its impact on concrete behavior is of considerable importance. Indeed, it is well known that the ITZ constitutes the weakest link in concrete. However, its mechanical properties are not widely known because direct mechanical characterization methods are difficult to perform. The nano-indentation technique, which is potentially the only one able to directly evaluate the mechanical properties of the interface, has its limitations due the great variability of the measurements $[14,15]$. That is why different authors have thus tried to perform tests with simplified models such as sandwiched specimens in which cement paste (or mortar) is in contact with coarse aggregate [16-25]. It has to be kept in mind that it is just a model interfacial system that allows producing a bond between matrix and aggregate. In fact, the material preparation (mixing) greatly affects the formation of ITZ in concrete [14-26]. Pope and Jennings [26] reported that the interfacial zone of a limestone mortar is reduced in size by controlling the water-aggregate contact through a pre-coating procedure or by mixing the cement paste separately. For sandwiched specimens (model interfacial system), the cement paste is generally prepared separately and then put in contact with an aggregate. This preparation method would simply make it possible to generate an interface similar to ITZ which probably has a different thickness than ITZ in concrete. Pope and Jennings [26] found that the size and character of the interfacial zone in model systems differ significantly from that seen in normal mortar systems. The size of the interfacial region in the model systems is much smaller $(10-20 \mu \mathrm{m})$ than the size of the interfacial region in mortar systems. Although these differences between the model and "real" interfaces exist, the artificial interface constitutes a simple approach to estimate the properties of the bond between cement paste and aggregate while bearing in mind its limits. Furthermore, the relevance of this artificial interface could be checked by inverse analysis, using the properties determined by this approach in multi-scale modeling [27-29].

The aim of this paper is to characterize the tensile and shear bond strengths between cement paste and aggregate after heating by original experiments at local scale. This characterization will contribute to the understanding of the damage mechanisms of concrete at high temperatures, and will be also used to propose local laws for a multi-scale modeling of concrete subjected to high temperatures.

\section{Experimental}

In the framework of MISt Laboratory, the experiments are performed at Laboratoire de Mécanique et Génie Civil (LMGC), in Montpellier (France). The purpose of these experiments is to characterize the tensile and shear bond strength between cement paste and limestone aggregate after heating.

\subsection{Materials}

The cement used is a Portland limestone cement CEM II/B-LL. The cement paste was prepared separately and then put in contact of the limestone aggregate. It was mixed in a standard mortar mixer with a water/ cement ratio (w/c) of 0.3 according to the following sequence: (1) pour water into mixer bowl, (2) add cement while stirring at low speed, (3) mix at low speed for $3 \mathrm{~min}$, then at high speed for $3 \mathrm{~min}$. 
The prismatic aggregates were cored from a single limestone rock. The material properties are given in Table 1.

Before casting, the cored aggregates are dried for $24 \mathrm{~h}$ at $105{ }^{\circ} \mathrm{C}$ inside a furnace to remove evaporable water and to ensure the same surface state (in term of water), and they are then positioned in specific molds $\left(10 \times 10 \times 30 \mathrm{~mm}^{3}\right)$. The molds are removed after $48 \mathrm{~h}$ of curing at $20{ }^{\circ} \mathrm{C}$ and high relative humidity ( $\sim 100 \%$ RH). After removing the molds, the prepared samples were stored in stable and controlled atmosphere, with temperature of $20^{\circ} \mathrm{C}$ and high relative humidity $(\sim 100 \% \mathrm{RH})$ in order to reduce the drying shrinkage.

\subsection{Sample}

The tested samples are of prismatic shape formed by a cement paste $\left(10 \times 10 \times 15 \mathrm{~mm}^{3}\right)$ in contact with a limestone aggregate $\left(10 \times 10 \times 15 \mathrm{~mm}^{3}\right)$ (Fig. 1a). This configuration makes it easy to calculate the stress from the measured force. About 138 samples were tested. Also, 15 samples of cement pastes were used to estimate the direct tensile strength of the bulk pastes.

As outlined in the introduction, the preparation method of samples and their geometric configuration allow only producing an artificial interface that differs from the interfacial transition zone in concrete in terms of the size and character [26].

\subsection{Heating process}

After 3 months of storage, the samples are subjected to heating in a furnace Nabertherm LH 216/12SW, with a heating rate of $1{ }^{\circ} \mathrm{C} / \mathrm{min}$, up to a set temperature (40, $\left.60,80,100,120,150{ }^{\circ} \mathrm{C}\right)$. The stabilization step at the set temperature lasts $1 \mathrm{~h}$. The cooling is performed naturally by maintaining the closed furnace.

\subsection{Mechanical tests}

The mechanical tests (tensile and shear tests) are performed with the MTS Universal Testing Machine $\mathrm{M} 1 / \mathrm{E}$ [30] at constant loading speed of $0.01 \mathrm{~mm} / \mathrm{s}$. To carry out the tensile test, the metal rods are bonded with special glue to the tested sample to fix it to the MTS Machine as illustrated in Fig. 1.

The device used for the shear test is shown in Fig. 1. It consists of two metal compartments and two plates $(9 \times 9 \mathrm{~mm})$ placed on the sides to apply a normal force. This normal force is measured using a force sensor (Omega LCMKD compression load 0-1000 N). For each test, the rupture strength is measured for each applied normal stress, which allows determining the interface cohesion and the friction angle (Coulomb criterion).

Before each test, the dimensions of the sample were measured for better determining the stress. All the tests were performed in triplicated.

\subsection{Scanning electron microscope observations}

In order to visualize the cracking facies of the cement paste-aggregate interface, the observations were carried out using scanning electron microscope (FEI QUANTA 200 FEG high resolution environmental SEM) before and after heating.

Table 2 summarizes all the tests performed with some results obtained.

\section{Results and discussion}

In this part, the results of the mechanical tests obtained are presented and discussed. For each test (tensile and shear), the results on the sound samples are first presented, then those on the samples that have undergone the heating process (degraded samples).
Table 1 Material data of used components

\begin{tabular}{llll}
\hline Aggregate & & Cement paste \\
\hline Size & $10 \times 10 \times 15 \mathrm{~mm}^{3}$ & Size & $10 \times 10 \times 15 \mathrm{~mm}^{3}$ \\
Origin & Limestone rock & Cement type & CEM II/B-LL 32.5 N \\
Density & $2.7 \mathrm{~g} / \mathrm{cm}^{3}$ & Density (measured) & $2.2 \mathrm{~g} / \mathrm{cm}^{3}$ \\
\hline
\end{tabular}




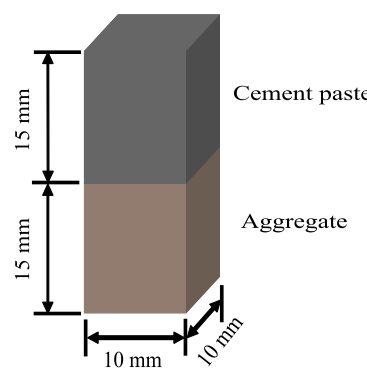

(a)

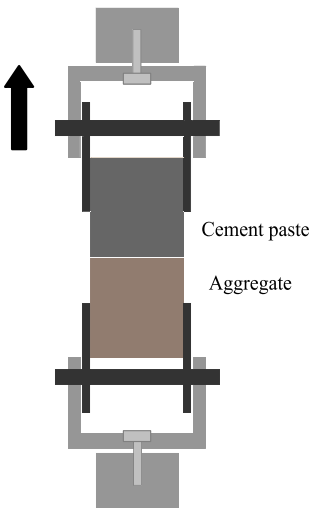

(b)

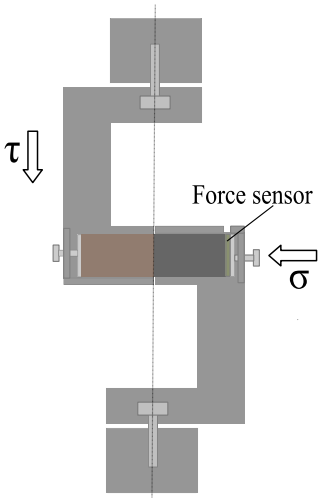

(c)

Fig. 1 Geometric configuration of the sample (a), tensile test (b) and shear test (c)

Table 2 The tests performed

\begin{tabular}{lllll}
\hline Temperature $\left({ }^{\circ} \mathrm{C}\right)$ & Tensile strength $f_{t}(\mathrm{MPa})$ & \multicolumn{2}{l}{ Shear strength $(\mathrm{MPa})$} & SEM observations \\
\cline { 3 - 4 } & & Cohesion $C(\mathrm{MPa})$ & Friction angle $\varphi\left({ }^{\circ}\right)$ & Tangential cracks \\
\hline 20 & 2.1 & 4.1 & 47.6 & 38.8 \\
60 & 1.2 & 3.0 & 33.3 & Tangential and radial cracks \\
80 & 0.6 & 2.6 & 28.8 & 26.2 \\
100 & 0.3 & 1.8 & 23.5 & 23.1 \\
120 & 0.2 & 1.1 & 1.1 & \\
150 & 0.2 & 0.7 & & \\
\hline
\end{tabular}

\subsection{Tensile tests}

\subsubsection{Sound samples}

The direct tensile test was performed on cement paste/ aggregate samples, as well as on cement paste samples. The latter have a dimension of $10 \times 10 \times 30 \mathrm{~mm}^{3}$ and were stored at $20{ }^{\circ} \mathrm{C}$ and $100 \%$ RH. For each hydration time, the mean tensile strength was determined on three samples. The evolution of the tensile strength of the cement paste is shown in Fig. 2. This figure shows a gradual increase in the tensile strength, which begins to stabilize at 2.5 MPa after 4 weeks of hydration. This strength value corresponds to the cement class used (CEM II/B-LL 32.5 N).

Figure 2 shows the evolution of the tensile bond strength between cement paste and aggregate. An

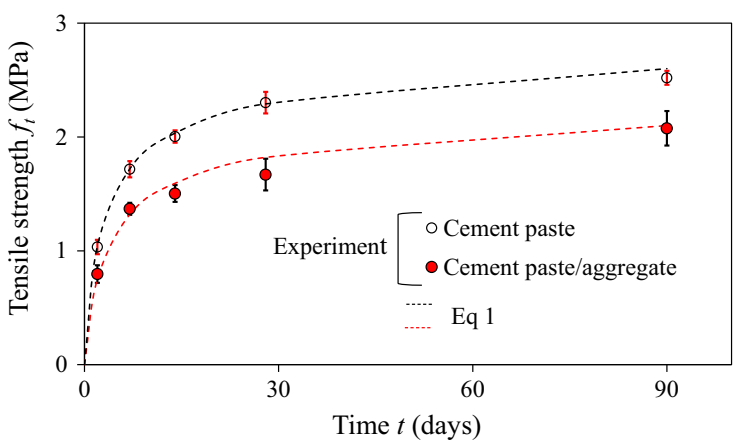

Fig. 2 Evolution of tensile strength $f_{t}$ of cement paste and cement paste-aggregate interface as a function of hydration time $(t)$

increase in bond strength is observed over time due to the development of the hydration. The tensile bond strength is $15-20 \%$ less than that of the bulk paste, but its evolution during hydration follows the same 
kinetics. Hsu and Slate [16] found that direct tensile bond strength between aggregate and paste varied from about 30-70\% of the tensile strength of the bulk paste, and dependent on the aggregate type (sandstone, granite, limestone), surface roughness of aggregate, and water to cement ratio (0.265-0.36). The tensile bond strength was higher with limestone aggregates. This bond strength increased as the water to cement ratio of the paste was reduced. Also, with increasing age, the bond strength increased. In our case, the direct tensile bond strength is close to that of the paste due to the low water to cement ratio $(\mathrm{w} / \mathrm{c}=0.3)$ and the nature of the aggregates used (limestone aggregates).

According to Grandet and Ollivier [31], the limestone aggregates develop epitaxy properties with the cement paste (calcium monocarboaluminate created by reaction with calcite), resulting in a more homogeneous transition zone. Figure 4 shows the cement paste-aggregate interface which appears homogenous, but the presence of the calcium monocarboaluminate should be confirmed by XRD spectrum or other evidences.

The evolution of tensile strength as function of the hydration time $(t)$ can be approximated by an exponential function (Eq. 1) such as that proposed in Eurocode [32] and plotted on Fig. 2:

$f_{t}(t)=f\left(t_{\infty}\right) \exp \left(k\left(1-\frac{t_{\infty}}{t}\right)^{0.5}\right)$

where $f\left(t_{\infty}\right)$ is the tensile strength which corresponds to almost complete hydration ( $t_{\infty}=90$ days), equal to 2.6 for cement paste and 2.1 for cement pasteaggregate bond, and $k$ is a fitting parameter of the evolution kinetics, equal to 0.16 for cement paste and 0.18 for cement paste-aggregate bond.

\subsubsection{Degraded samples}

The tensile tests were performed on cement pasteaggregate samples after they had undergone the heat treatment. The samples were heated and tested after three months of curing at $20{ }^{\circ} \mathrm{C}$ and $100 \% \mathrm{RH}$. Figure 3 shows the evolution of tensile bond strength between cement paste and aggregate depending on the temperature. One can note a gradual decrease in tensile bond strength which is approximately $71 \%$ at $60{ }^{\circ} \mathrm{C}$ and about $90 \%$ at $120{ }^{\circ} \mathrm{C}$. This loss of strength could be due to several factors. First, the ettringite

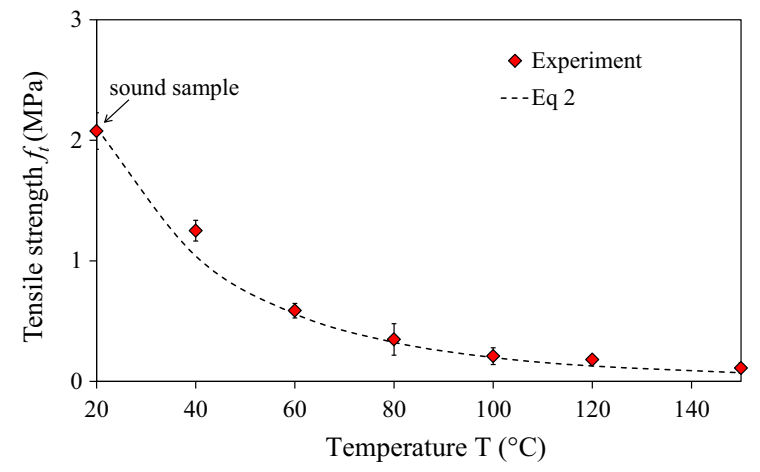

Fig. 3 Evolution of tensile strength $f_{t}$ of cement pasteaggregate interface after heating versus temperature $(T)$

which is unstable in temperature dissolves in the pore solution at $70{ }^{\circ} \mathrm{C}$ releasing a large amount of water $[33,34]$ and is completely dissolved at $100{ }^{\circ} \mathrm{C}[3]$. The high concentration of ettringite at the cement pasteaggregate interface [35] makes that its dissolution may weaken the interface.

However, the main mechanism to explain the decrease in tensile bond strength with heating is the significant difference in the thermal expansion between the cement paste and the aggregates [2]. Indeed, the coefficient of thermal expansion (CTE) of the limestone aggregates increases as a function of temperature. It varies between 3 and $10 \mu \mathrm{m} / \mathrm{m} / \mathrm{K}$ when the temperature increases from 20 to $80{ }^{\circ} \mathrm{C}$ and reaches $17 \mu \mathrm{m} / \mathrm{m} / \mathrm{K}$ at $300{ }^{\circ} \mathrm{C}$ [36]. The cement paste has a coefficient of thermal expansion between 10 and $30 \mu \mathrm{m} / \mathrm{m} / \mathrm{K}$. The CTE of cement paste decreases when temperature increases $[6,36]$. This difference in coefficient of thermal expansion causes differential deformations (thermal mismatch mechanism), which induce a system of internal stresses leading to tangential cracks [37] as shown in Fig. 4. Hettema [38] shows that when the CTE of inclusion (aggregate) is greater than of the matrix (cement paste), the result is the formation of radial cracks within the matrix. On the other hand, the tangential cracks develop at the inclusion/matrix interface when the CTE of inclusion is lower than of the matrix. The radial cracks occur when the temperature is above $150{ }^{\circ} \mathrm{C}$, while the tangential cracks occur when the temperature is below $150{ }^{\circ} \mathrm{C}[6,37,39]$. Figure 4 shows a beginning of radial cracks in the cement paste heated to $120{ }^{\circ} \mathrm{C}$ which suggesting that the CTE of aggregates becomes close to or greater than that of the paste. 


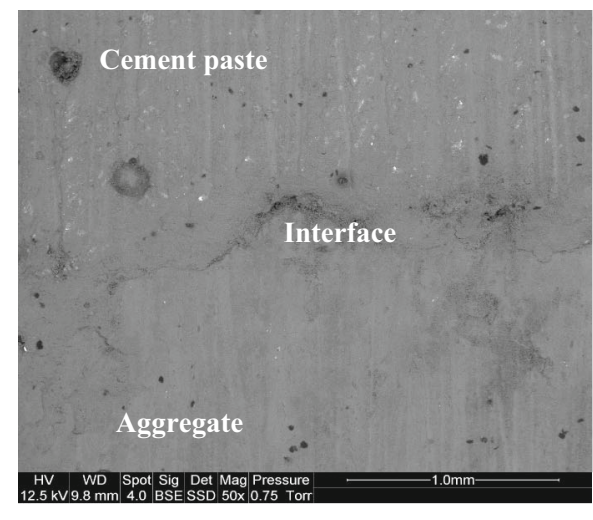

Sound sample $\left(20^{\circ} \mathrm{C}\right)$

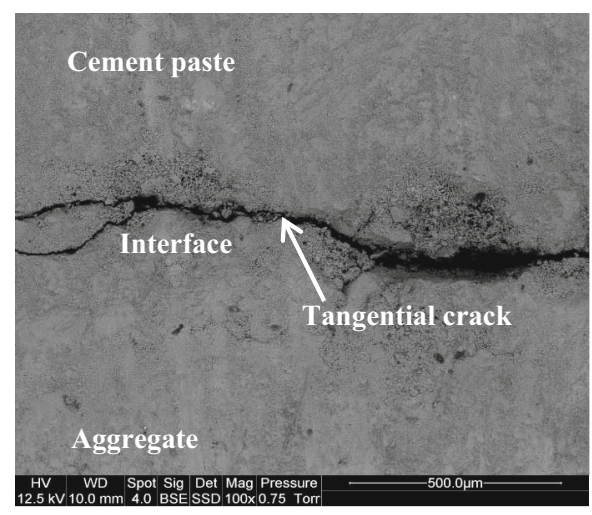

Degraded sample $\left(100^{\circ} \mathrm{C}\right)$

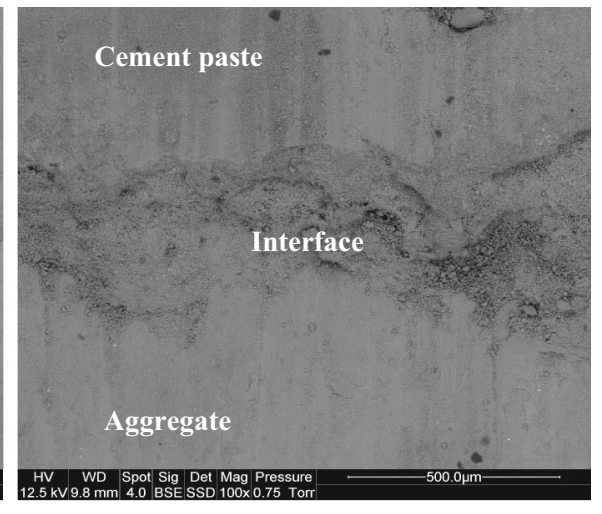

Degraded sample $\left(80^{\circ} \mathrm{C}\right)$

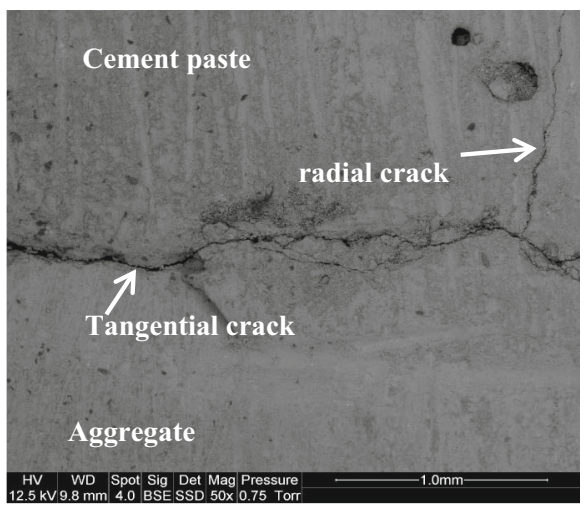

Degraded sample $\left(120^{\circ} \mathrm{C}\right)$

Fig. 4 SEM photos showing cement paste-aggregate interface before and after heating; image with detection of backscattered electrons (BSE)

In addition, the free water present in the capillary porosity and a portion of the bound water evaporate. This loss of water leads to a drying shrinkage of the paste, which is activated with temperature rise [36]. Thus, the behavior of the heated cement paste begins with a thermal expansion due to heating process. Then, if no precautions are taken against the drying during the heating, there is a contraction phase [36]. So there is a competition between drying shrinkage and thermal expansion which accentuates the incompatibility of deformation between the paste and the aggregate.

The evolution of tensile bond strength as a function of temperature $(T)$ can also be approximated by an exponential function (Eq. 2), as illustrated in Fig. 3:

$f_{t}(T)=f\left(T_{\text {ref }}\right) \exp \left(k_{\text {th }}\left(\frac{T_{\text {ref }}}{T}-1\right)\right)$

where $f\left(T_{\text {ref }}\right)$ is the tensile strength at the reference temperature $\left(T_{\text {ref }}=20{ }^{\circ} \mathrm{C}\right)$, equal to $2.1 \mathrm{MPa}$, and $k_{\text {th }}$ is a calibration parameter determined by fitting the relationship presented in (Eq. 2) with experimental results. This parameter is equal to 11 .

\subsection{Shear tests}

\subsubsection{Sound samples}

The shear test is carried out on cement paste/aggregate samples after three months of curing at $20{ }^{\circ} \mathrm{C}$ and $100 \%$ RH. Figure 5 shows the evolution of shear bond strength as a function of the normal stress. It may be noted that the shear strength increases linearly with the normal stress. Taylor and Broms [17] found the same results by using sandwiched specimens.

So, we can assume that the shear behavior of the interface follows a linear trend as Mohr-Coulomb model (failure criterion) (Eq. 3) which allows accessing to the cohesion and the internal friction angle by: 


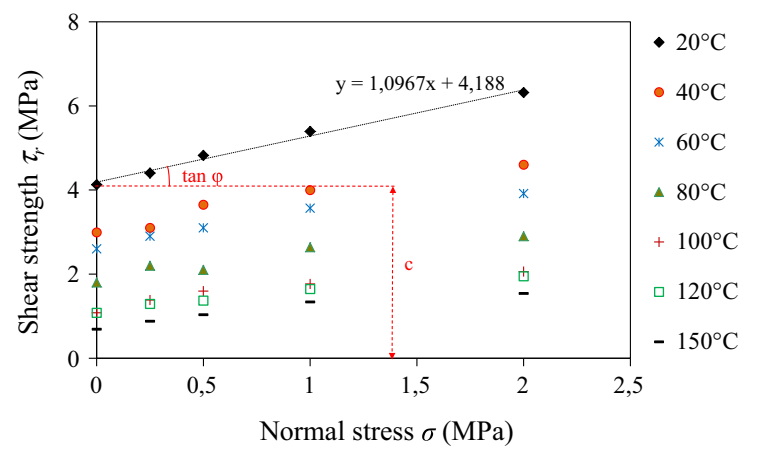

Fig. 5 Evolution of shear strength of cement paste-aggregate interface versus normal stress and temperature

$\tau_{r}(\sigma)=c+\sigma \tan (\phi)$

where $\tau_{r}$ is the shear stress at rupture (MPa), $\sigma$ the applied normal stress (MPa), $\varphi$ the friction angle and $\mathrm{c}$ the cohesion (MPa).

The friction angle is of about $48^{\circ}$ for sound sample. According to Taylor and Broms [17] and Gu et al. [22], this friction angle corresponds to a failure mode by slip at the interface rather than crushing of the paste. In order to examine the effect of the strength and surface condition of coarse aggregate on the fracture of concrete, Kosaka et al. [19] performed shear bond test on specimens consisted of a cylindrical coarse aggregate and mortar matrix. They showed that shear bond strength depends on the curing condition, type of aggregate and surface roughness. The shear bond test allowed identifying a friction angle ranged between $30^{\circ}$ and $40^{\circ}$.

\subsubsection{Degraded samples}

Figure 5 shows the evolution of shear strength according to the normal stress for different temperature of heating $\left(20,40,60,80,100,120\right.$ and $\left.150{ }^{\circ} \mathrm{C}\right)$. For a fixed normal stress, the shear bond strength decreases as a function of temperature.

The evolution of cohesion as function of heating temperature is shown in Fig. 6a. During heating, a progressive decrease in the cohesion can be observed. A weakening of the interface is then noticed when the heating temperature increases. The cause of this weakening is mainly due to the thermal mismatch mechanism. This loss of bonding between the aggregate and the paste can be illustrated by the decrease of the internal friction angle (Fig. 6b) during heating.

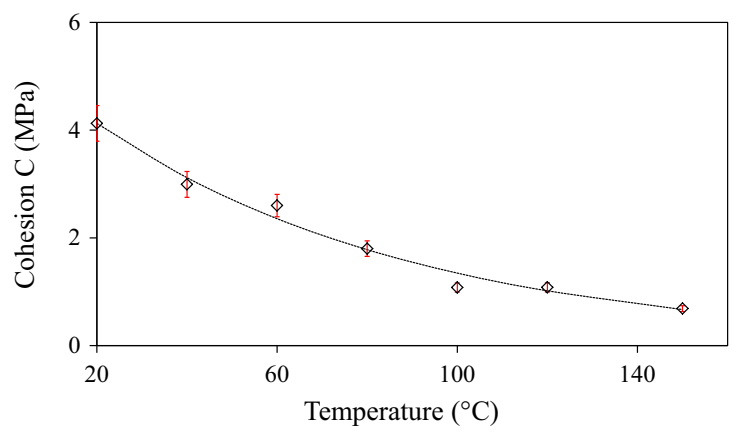

(a)

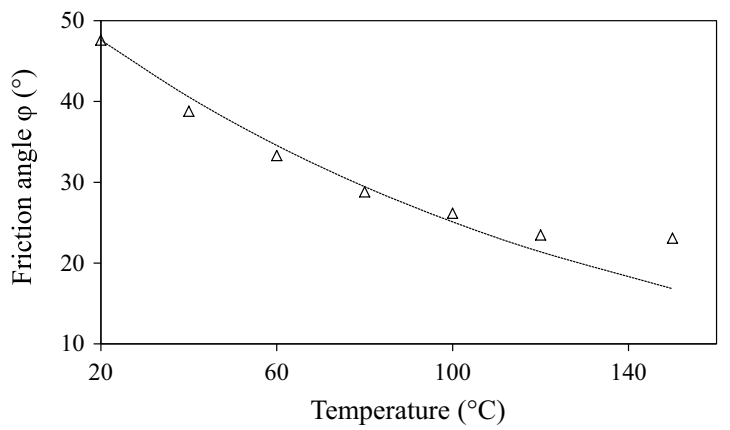

(b)

Fig. 6 Evolution of cohesion (a) and friction angle (b) during shear test

Thus, when the interface undergoes heating, the loss of contact facilitates the slip between the paste and aggregate, which reduces the friction.

The evolution of cohesion and internal friction angle as a function of temperature $(T)$ can also be approximated by an exponential function (Eq. 4), as illustrated in Fig. 6:

$X_{i}(T)=X_{i}\left(T_{\text {ref }}\right) \exp \left(a_{i} \times\left(T_{\text {ref }}-T\right)\right)$

where $i=$ cohesion $C$ or internal friction angle $\varphi$, $X_{i}\left(T_{\text {ref }}\right)$ is cohesion $C$ (or internal friction angle $\varphi$ ) at the reference temperature $\left(T_{\text {ref }}=20{ }^{\circ} \mathrm{C}\right)$ and $a_{i}$ a calibration parameter determined by fitting the exponential function (Eq. 4) with the experimental results.

Figure 7 shows the evolution of cohesion $C /$ tensile bond strength $f_{t}$ ratio as a function of temperature with a ratio of about 2 at $20{ }^{\circ} \mathrm{C}$, in accordance with the results obtained by Nguyen [18]. Note that $C / f_{t}$ ratio increase progressively as a function of temperature, which shows that the tensile bond strength is more affected by the thermal damage than the shear bond strength. This could be explained by the fact that the modes of rupture are different. In the case of direct 


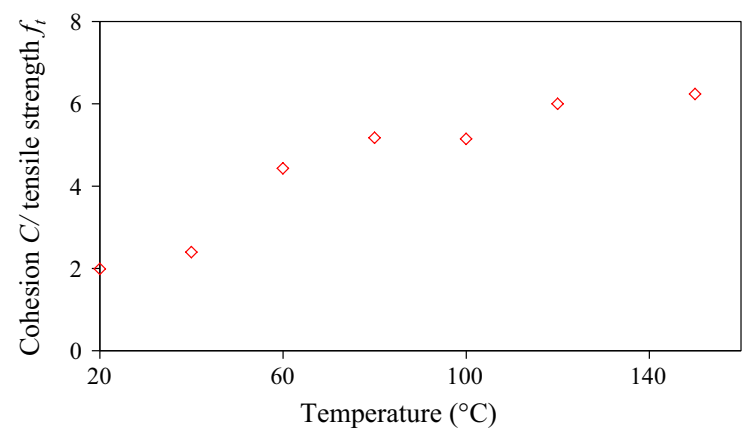

Fig. 7 Evolution of cohesion $C /$ tensile bond strength $f_{t}$ ratio as a function of temperature

tensile test, the failure occurs by decohesion (mode I), whereas in the case of shear test, the failure occurs by sliding (mode II) which generates a residual resistance due to friction of the lips of cracks [40].

\section{Summary}

The experimental program performed in this work allowed characterizing the tensile and shear bond strengths between cement paste and limestone aggregate. It reveals that:

1. the tensile bond strength is $20 \%$ lower than that of the cement paste, and evolves during hydration with the same kinetics as cement paste. The tensile bond strength decreases as the heating temperature increases. It decreases by $71 \%$ at $60{ }^{\circ} \mathrm{C}$ and about $90 \%$ at $120{ }^{\circ} \mathrm{C}$. This strength decrease is mainly due to the weakening of the interface by the thermal mismatch mechanism.

2. the shear bond strength increases almost linearly with the increase of the normal stress. Thus, assuming that the evolution follows the MohrCoulomb model, the changes in cohesion and friction angle as a function of temperature are determined. A gradual decrease is observed in cohesion and friction angle, reflecting a decrease of adhesion properties between the cement paste and limestone aggregate.

3. the direct tensile bond strength is more affected by the thermal degradation than the shear bond strength.

\section{Compliance with ethical standards}

Conflict of interest The authors declare that they have no conflict of interest.

\section{References}

1. Alonso C, Fernandez L (2004) Dehydration and rehydration processes of cement paste exposed to high temperature environments. J Mater Sci 39(9):3015-3024

2. Bažant Z, Kaplan M (1996) Concrete at high temperature: material behaviour and mathematical modelling. Longman, London, p 412

3. Castellote M, Alonso C, Andrade C, Turrillas X, Campo J (2004) Composition and microstructural changes of cement pastes upon heating, as studied by neutrondiffraction. Cem Concr Res 34(9):1633-1644

4. Dias W, Khoury G, Sullivan P (1990) Mechanical properties of hardened cement paste exposed to temperatures up to $700^{\circ} \mathrm{C}$. ACI Mater J 87(2):160-166

5. Khoury G, Sullivan G (1988) Research at imperial college on the effect of elevated temperatures on concrete. Fire Saf J 13(1):69-72

6. Piasta J (1984) Heat deformation of cement phases and microstructure of cement paste. Mater Struct Res Test RILEM 17(102):415-420

7. Ulm F, Coussy O, Bažant Z (1999) The "Channel" fire II: analyses of concrete damage. J Eng Mech 125(3):283-289

8. Schrefler B, Brunello P, Gawin D, Majorana C, Pesavento F (2002) Concrete at high temperature with application to tunnel fire. Comput Mech 29(1):43-51

9. De Sa C, Benboudjema F (2011) Modeling of concrete nonlinear mechanical behavior at high temperatures with different damage-based approaches. Mater Struct 44(8):1411-1429

10. Dal Pont S, Meftah F, Schrefler B (2011) Modeling concrete under severe conditions as a multiphase material. Nucl Eng Des 241(3):562-572

11. Ollivier J, Maso J, Bourdette B (1995) Interfacial transition zone in concrete. Adv Cem Based Mater 2(1):30-38

12. Scrivener K, Crumbie A, Laugesen $P$ (2004) The interfacial transition zone (ITZ) between cement paste and aggregate in concrete. Interface Sci 12:411-421

13. Breton D, Carles-Gibergues A, Ballivy G, Grandet J (1993) Contribution to the formation mechanism of the transition zone between rock-cement paste. Cem Concr Res 23:335-346

14. Li W, Xiao J, Sun Z, Kawashima S, Shah S (2012) Interfacial transition zones in recycled aggregate concrete with different mixing approaches. Constr Build Mater 35:1045-1055

15. Xiao J, Li W, Sun Z, Lange D, Shah S (2013) Properties of interfacial transition zones in recycled aggregate concrete tested by nanoindentation. Cem Concr Compos 37:276-292

16. Hsu T, Slate F (1963) Tensile bond strength between aggregate and cement paste or mortar. ACI J 60(4):465-485

17. Taylor M, Broms B (1964) Shear bond strength between coarse aggregate and cement paste or mortar. ACI J 61(8):939-958 
18. Nguyen T (2013) Etude de la zone d'interphase "granulats calcaires poreux-pâte de ciment": Influence des propriétés physico-mécaniques des granulats; conséquences sur les propriétés mécaniques du mortier, École Nationale Supérieure des Mines de Saint-Etienne, France. PhD Thesis

19. Kosaka Y, Tanigawa Y, Oota F (1975) Effect of coarse aggregate on fracture behavior of concrete. Trans Archit Inst Jpn 228:1-12

20. Al Attar T (2013) A quantitative evaluation of bond strength between coarse aggregate and cement mortar in concrete. Eur Sci J 9(6):46-60

21. Husem M (2003) The effects of bond strengths between lightweight and ordinary aggregate-mortar, aggregate-cement paste on the mechanical properties of concrete. Mater Sci Eng A 363(1):152-158

22. Gu X, Hong L, Wang Z, Lin F (2013) Experimental study and application of mechanical properties for the interface between cobblestone aggregate and mortar in concrete. Constr Build Mater 46:156-166

23. Sicat E, Gong F, Ueda T, Zhang D (2014) Experimental investigation of the deformational behavior of the interfacial transition zone (ITZ) in concrete during freezing and thawing cycles. Constr Build Mater 65:122-131

24. Jebli M, Jamin F, Garcia-Diaz E, El Omari M, El Youssoufi M (2016) Influence of leaching on the local mechanical properties of an aggregate-cement paste composite. Cem Concr Compos 73:241-250

25. Zibelmann R (1987) A method for strengthening the bond between cement stone and aggregates. Cem Concr Res 17:651-660

26. Pope A, Jennings H (1992) The influence of mixing on the microstructure of the cement paste/aggregate interfacial zone and on the strength of mortar. J Mater Sci 27:6452-6462

27. Unger J, Eckardt S (2011) Multiscale modeling of concrete: from mesoscale to macroscale. Arch Comput Methods Eng 18:341-393

28. Carraraa P, Wua T, Krusea R, De Lorenzisa L (2016) Towards multiscale modeling of the interaction between transport and fracture in concrete. RILEM Tech Lett 1:94-101

29. Palmieri V, De Lorenzis L (2014) Multiscale modeling of concrete and of the FRP-concrete interface. Eng Fract Mech 131:150-175
30. MTS Systems Corporation. www.mts.com/2002

31. Grandet J, Ollivier J (1980) Etude de la formation du monocarboaluminate de calcium hydraté au contact d'un granulat calcaire dans une pâte de ciment Portland. Cem Concr Res 10(6):759-770

32. European Committee for standardization (2004) EN 1992-1-2: 2004 eurocode 2: design of concrete structures, CEN

33. Heinz D, Ludwig U (1987) Mechanism of secondary ettringite formation in mortars and concretes subjected to heat treatment. In: Concrete durability. Katharine and Bryant Mather international symposium SP-100, American Concrete Institute, Farmington Hills, Michigan, pp 2059-2071

34. Collepardi M (2003) A state of the art review on delayed ettringite attack on concrete. Cem Concr Compos 25(4-5):401-407

35. Grandet J, Ollivier J (1980) New method for the study of cement-aggregate interfaces. In: Proceedings of the 7th international congress on the chemistry of cement III, editions septima, Paris, pp 85-89

36. Cagnon H, Vidal T, Sellier A, Soula C, Bourbon X, Camps G (2016) Effects of water and temperature variations on deformation of limestone aggregates, cement paste, mortar and high performance concrete (HPC). Cem Concr Compos 71:131-143

37. Fu Y, Wong Y, Poon C, Tang C, Lin P (2004) Experimental study of micro/macro crack development and stress-strain relations of cement-based composite materials at elevated temperatures. Cem Concr Res 34:789-797

38. Hettema M (1996) The thermo-mechanical behaviour of sedimentary rock: an experimental study. PhD Thesis, Delft University

39. Al Nahhas F (2004) Comportement thermo-mécanique des murs en maçonnerie de blocs creux en béton sous l'action d'un feu conventionnel," PhD thesis, Université de MarneLa-Vallée

40. Rao G, Prasad B (2002) Influence of the roughness of aggregate surface on the interface bond strength. Cem Concr Res 32:253-257 